\title{
Concentrated Solar Power Site Suitability using GIS-MCDM Technique taken UAE as a Case Study
}

\author{
Mohammad Basheer Alqaderi ${ }^{1}$ \\ Dept. of Engineering projects \\ management, Isra University \\ Amman, Jordan
}

\author{
Walid Emar ${ }^{2}$ \\ Dept. of Electrical Engineering \\ Isra University \\ Amman, Jordan
}

\author{
Omar A. Saraereh ${ }^{3}$ \\ Dept. of Electrical Engineering \\ Hashemite University \\ Zarqa, Jordan
}

\begin{abstract}
In recent years, countries have begun to reduce the consumption of fossil fuels and replace them with renewable energy resources in order to mitigate the effects of fossil fuels on the environment and save money besides increasing energy security. This paper has investigated the suitability map for the large-scale projects in concentrated solar power (CSP) in United Arab Emirates (UAE) using GIS data and multi-criteria decision making technique (MCDM). The suitability map is composed of multi-maps (layers) of solar irradiation [Direct Normal irradiance (DNI) component], land slope, protected areas, land use, proximity to water bodies, power grid and the roads. Then, Analytic Hierarchy Process (AHP) method is applied to identify the weights of ranking criteria. The paper has highlighted the most-suitable location as well as non-suitable location among UAE to install CSP projects. The study's results proved that UAE have multi-hotspot locations can be exploited for CSP projects.
\end{abstract}

Keywords-Analytic hierarchy process (AHP); concentrated solar power (CSP); multi-criteria decision making (MCDM); direct normal irradiance (DNI); United Arab Emirates (UAE); hot-spot locations

\section{INTRODUCTION}

Middle East has great potential for Renewable Energy (RE), but right now RE projects form only $1 \%$ of energy mix within the region [1]. Abu Dhabi's renewable target, one of UAE emirates, is to produce $7 \%$ of its electricity from renewable sources by 2020. Despite the huge ongoing projects in Abu Dhabi, a glance at the statistics shows that the emirate's installed generation capacity from renewable sources in 2013 was 111 megawatts which is $1 \%$ of total energy mix [3].

United Arab Emirates set in its main energy plan to generate electricity from CSP and PV systems, however selecting the suitable location and areas to install large-scale CSP and PV projects is not easy but represents a primary task that must be done early in the stage of planning. The selecting of suitable locations that will host CSP and PV plants depend not only on the amount of solar radiation received but also depends on several conflicting factors which shall be taken into decision maker's consideration like technological factors (grid connectivity), environmental factors (protected areas and water bodies), economic, social factors (population density), topographic factors (water availability, road proximity and grid proximity) and elevation [2].
To solve such a conflicting problem's factors, this research will use the geographical information system (GIS maps) and multi-criteria decision making (MCDM) technique to produce suitability map of the entire UAE state to have large scale CSP installation. Through MCDM approach, the analytic hierarchy process (AHP) technique has been applied to determine the multi-stage hierarchical structure.

Multiple-criteria decision-making (MCDM) or multiplecriteria decision analysis (MCDA), popularized by Stanley Zionts (1979) is MCDM or MCDA are well-known acronyms for multiple-criteria decision-making and multiple-criteria decision analysis. Conflicting criteria are typical in evaluating options: cost or price is usually one of the main criteria, and some measure of quality is typically another criterion, easily in conflict with the cost. MCDM is concerned with structuring and solving decision and planning problems involving multiple criteria. The purpose is to support decision-makers facing such problems. Typically, there does not exist a unique optimal solution for such problems and it is necessary to use decision-maker's preferences to differentiate between solutions.

The Analytic Hierarchy Process (AHP), introduced by Thomas Saaty (1980), is an effective tool for dealing with complex decision making, and may aid the decision maker to set priorities and make the best decision. The AHP generates a weight for each evaluation criterion according to the decision maker's pairwise comparisons of the criteria. The AHP generates a weight for each evaluation criterion according to the decision maker's pairwise comparisons of the criteria. Finally, the AHP combines the criteria weights and the options scores, thus determining a global score for each option, and a consequent ranking. The global score for a given option is a weighted sum of the scores it obtained with respect to all the criteria.

The data were collected using various methods such as Geographic Information System (GIS) analysis combined with Multi-criteria Decision Making (MCDM) technique. The pairwise matrix data, used to develop MCDM-AHP technique, were conducted from literature studied based on experts opinions, the data used to build model then determine proposed location and usage for RE projects and resources from multi Hotspot locations in UAE using commercial software ArcMap (version 10.3.1). Data were analyzed to investigate the site suitability. 
The GIS data were downloaded from different online sources based on satellite images. The GIS combined with MCDM will be used to identify CSP and PV hotspot area in United Arab Emirates. The process of identifying hotspot areas will be discussed in two parts, in the first part, the unsuitable areas within UAE will be discussed just to mask the areas that are not suitable to build CSP and PV projects. Then in the second part MCDM represented by AHP technique will be used in order to weight the decision areas and ranking criteria as shown in Fig. 1.

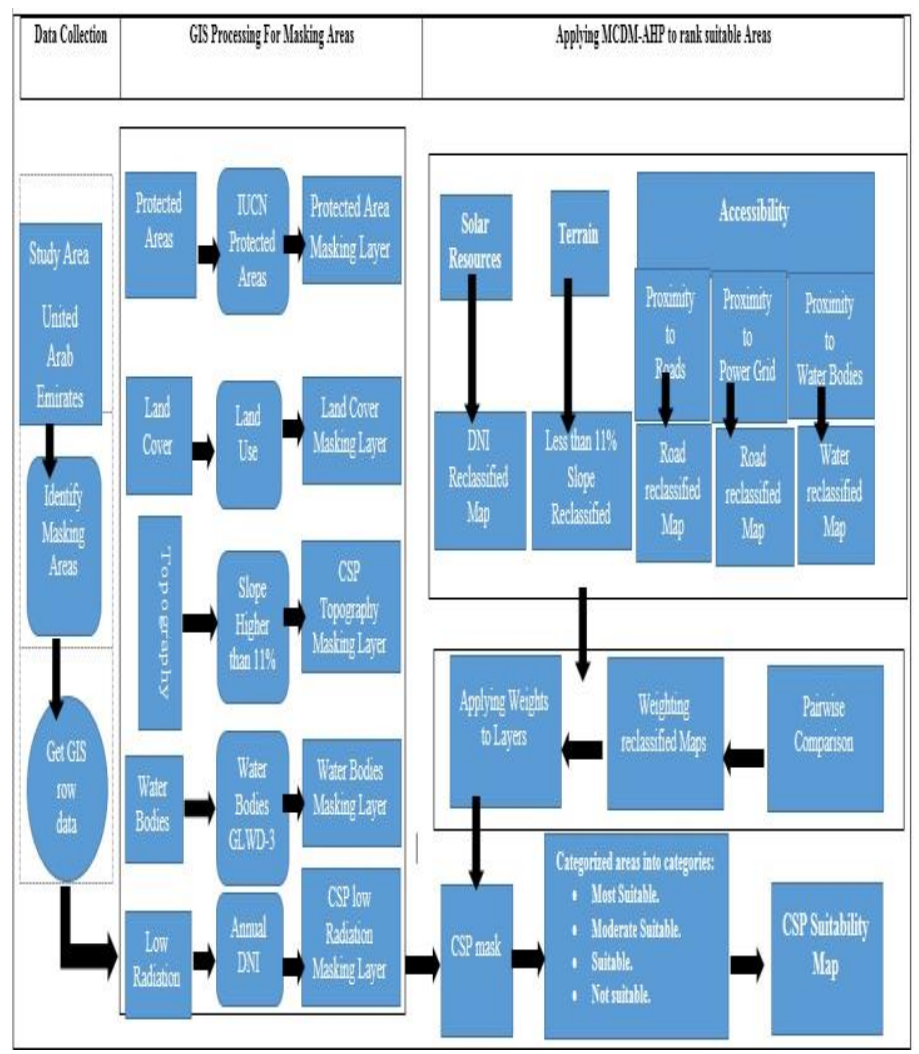

Fig. 1. Methodology process.

\section{GIS TOOL}

GIS is a helpful tool for the analysis of maps and geographical information. Furthermore GIS represents powerful tool to identify renewable energy potential sites that help policymaker to decide optimal locations for installing renewable energy projects.

The idea of the solution is that the optimal location, where to install solar plant, must comply some conditions, for example, the location must be unused, it should have a suitable solar radiation, doesn't represent water body, has an elevation suitable for adapting the proposed technology and far from future urban location as well as near to power Grid. The five steps in the analysis process are:

\section{1) Exclusion of Unsuitable Areas}

Firstly, the study will exclude areas that are not suitable for building large-scale CSP projects. Identifying those areas requires spatial data analysis. The data includes geographical factors, infrastructure factors, terrain factors, land cover factor, solar potential factor, land use factor, elevation and slope factor.

\section{A. Protected Areas}

International union for conservation of nature IUCN defined the protected areas as: "a clearly defined geographical space, recognized, dedicated and managed, through legal or other effective means, to achieve the long term conservation of nature with associated ecosystem services and cultural values "[3]. IUCN defined six categories of protected areas which are: Strict Nature Reserve, Wilderness Area, National Park, Natural Monument or Feature, Habitat/Species Management Area and Protected Landscape/Seascape [3].

United Arab Emirates has 44 protected areas, the area of land area protected is $12296 \mathrm{Km}^{2}$ while the area of marine area protected is $2336 \mathrm{Km}^{2}$. Protected areas include parks, wild areas and nature reserves, those areas represent biodiversity conservation [4].

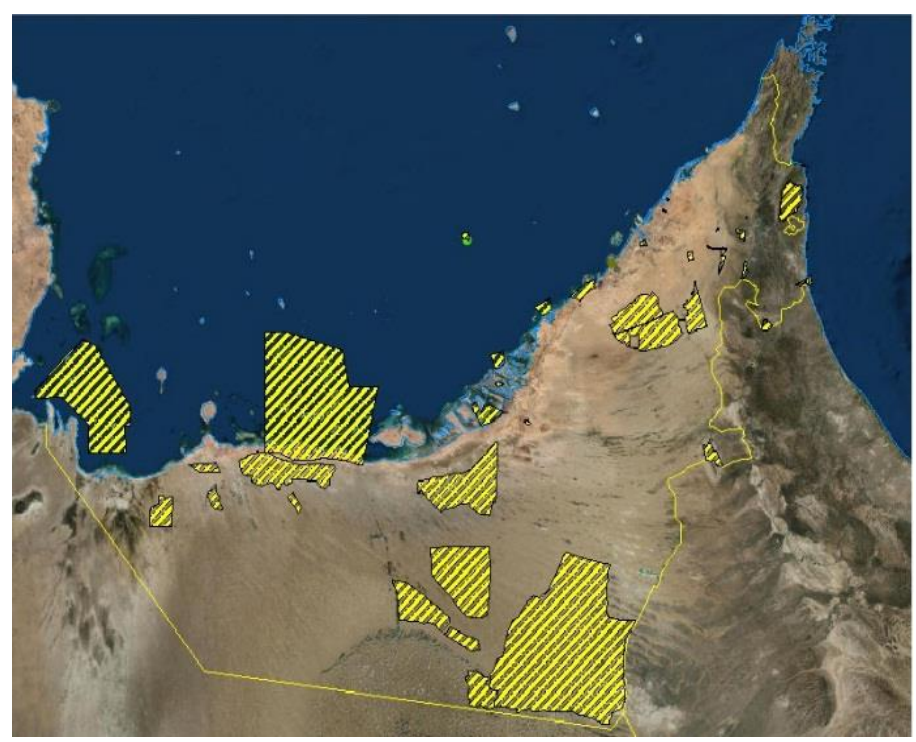

Fig. 2. UAE protected areas map.

Fig. 2 shows the UAE protected areas which shaded in yellow color. The information regarding protected areas was obtained from project of world database on protected area (WDPA). The map shown in Fig. 2 represents first mask layer to be excluded when performing GIS analysis.

\section{B. Land Cover Area}

A large scale CSP projects require large-scale areas compared with traditional power generating plants. Therefore, it is necessary to assign areas that not occupied by other land uses. The information regards land cover was obtained from European space Agency Globcover database map (ESA) 2009.

International Globcover map contains 23 categories for land use, among those categories only two categories mainly existing in UAE that will be considered in exclusion areas. Fig. 3 shows in colors such areas:

- Ginger Pink color: refers to value " 190 " in GlobCover Land Cover Classes, which means Artificial surfaces 
and associated areas (Urban areas $>50 \%$ ). This area represents $1 \%$ of total country's area [5].

- Yellow color: refers to value " 210 " in glob cover land cover classes, which means small size water bodies, similarly this area covers less than $1 \%$ of total area [5].

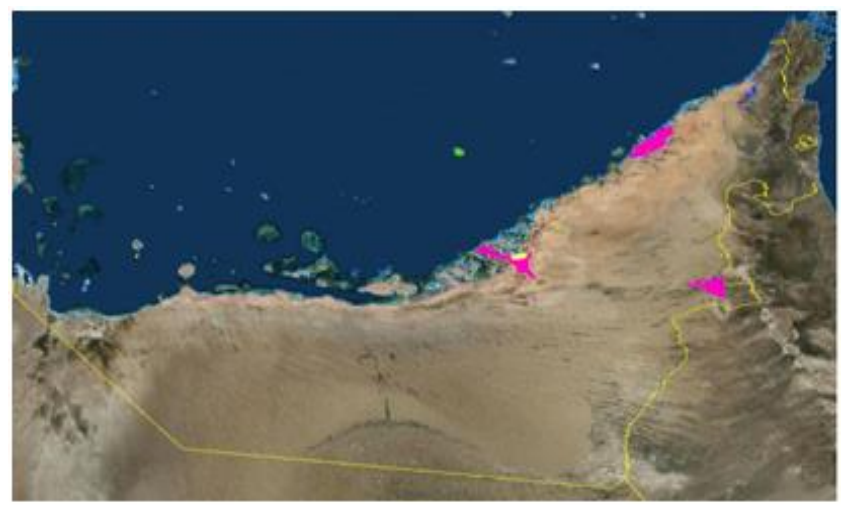

Fig. 3. UAE land cover map.

\section{Topography}

It is recommended for large scale solar projects to be installed on flat area especially CSP plants. The terrain slope value is the main factor that determines whether this area is suitable to construct solar power plant or not, so the study will use the slope as ranking criteria in our study. Many more studies were done to determine the proper value for suitable land slope. The studies concluded that the semi-flat areas is suitable being have high solar exposure, conversely the steep areas increase the project installation cost as well as maintenance cost [2]. In this paper, the lands with slope less than $4 \%$ are considered, while the slopes higher than $4 \%$ are not considered. Fig. 4 shows the digital elevation model obtained from U.S. geological survey (USGS) with one arc second resolution $(30 \mathrm{M})$ with $95 \%$ confident level [8]-[10].

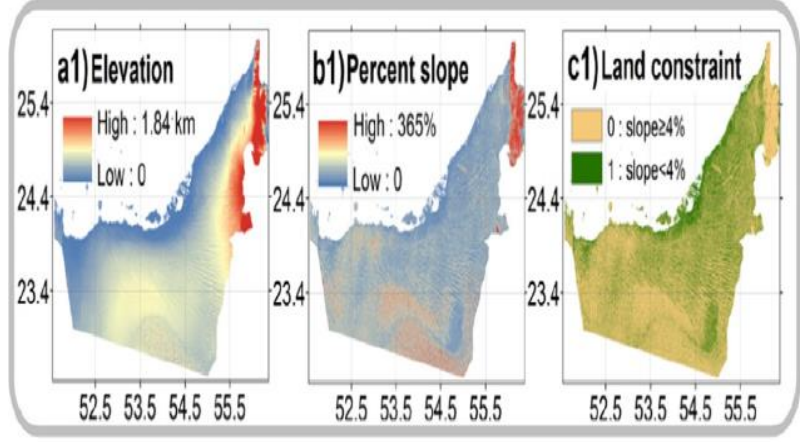

Fig. 4. a1) UAE map elevation; b1) percent slope; c3) land constraint.

\section{Water Bodies}

The data regards water bodies including lakes, reservoirs and rivers, water bodies that will be used as excluded mask from suitable areas map [6]. Fig. 5 below shows the water bodies' map, where the water body location is shaded by Blue color. The data regarding water bodies is provided by the Global Lakes and Wetlands Database (GLWD). GLWD consists of three data levels: GLWD-1, GLWD-2, and GLWD-3. In this paper GLWD-3 is used which has high resolution (30 arc-second) as well as contains all data exist in the lower two levels [6].

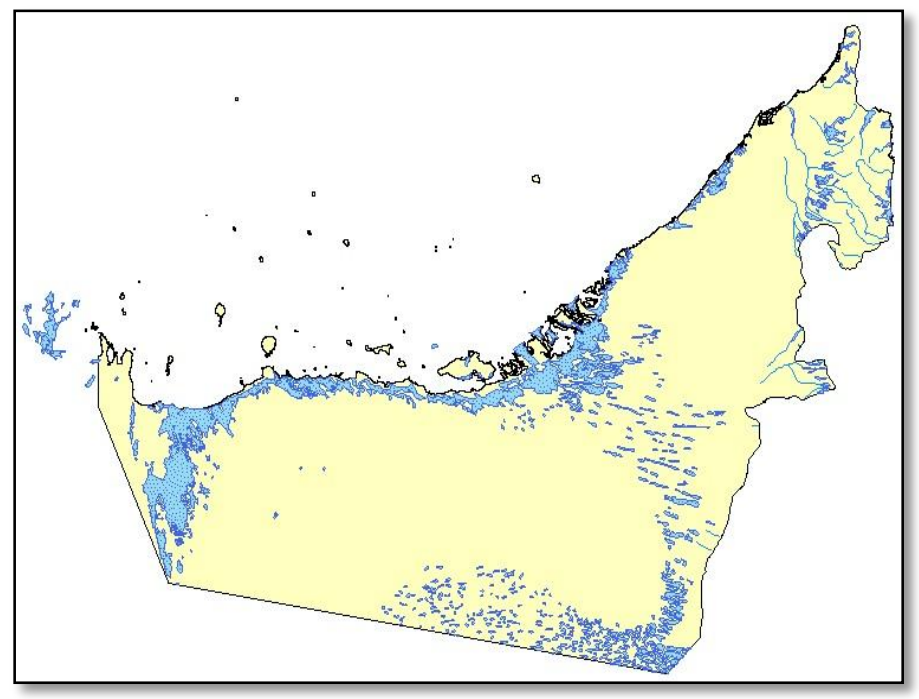

Fig. 5. UAE water bodies map.

\section{E. Low Solar Radiation}

Sun radiation goes through multiple changes until it reaches the surface of earth. These changes are related to the atmosphere as well as the topography of the earth. Radiation reaches the earth surface either direct or reflected or diffused, all those three types represent global solar radiation. Solar radiation is the main source of solar power CSP and PV technologies. The direct normal irradiance (DNI) represents the source of specific cooling power (SCP) technology. DNI is the amount of solar radiation at the flat earth's surface perpendicular to sun's beam while the sky radiation is blocked. In order to install feasible large-scale solar project, the area intended to be used shall meet the minimum radiation levels required by each technology. Experimentally the commercial CSP projects have been installed on areas with annual DNI greater than $1800 \mathrm{KWh} / \mathrm{m}^{2}$. Hence throughout this study the areas with annual DNI less than $1800 \mathrm{KWh} / \mathrm{m}^{2}$ will be excluded in mask map (assigned low weight) [7]. The source data regarding Global Horizontal Irradiance (GHI) and DNI are obtained from MASDAR Solar atlas [8].

The UAE monthly maps for the DNI and GHI are shown in Fig. 6. Note that for DNI component, it presents higher values approximately $170 \mathrm{~W} / \mathrm{m}^{2}$, during March, April, May (spring season), September and October (autumn). Furthermore, the lower values were registered in summer and winter in which the minimum value was approximately $130 \mathrm{~W} / \mathrm{m}^{2}$ [7]. The average annual sum of DNI varies between $1600 \mathrm{KW} / \mathrm{m}^{2}$ and $2300 \mathrm{KW} / \mathrm{m}^{2}$ as shown in Fig. 7. The best areas to install CSP projects are the places where DNI is greater than $1800 \mathrm{KW} / \mathrm{m}^{2}$ whereas the locations that are greater than $1800 \mathrm{MW} / \mathrm{m}^{2}$ represent more than $70 \%$ of country area at the southern part of UAE. 


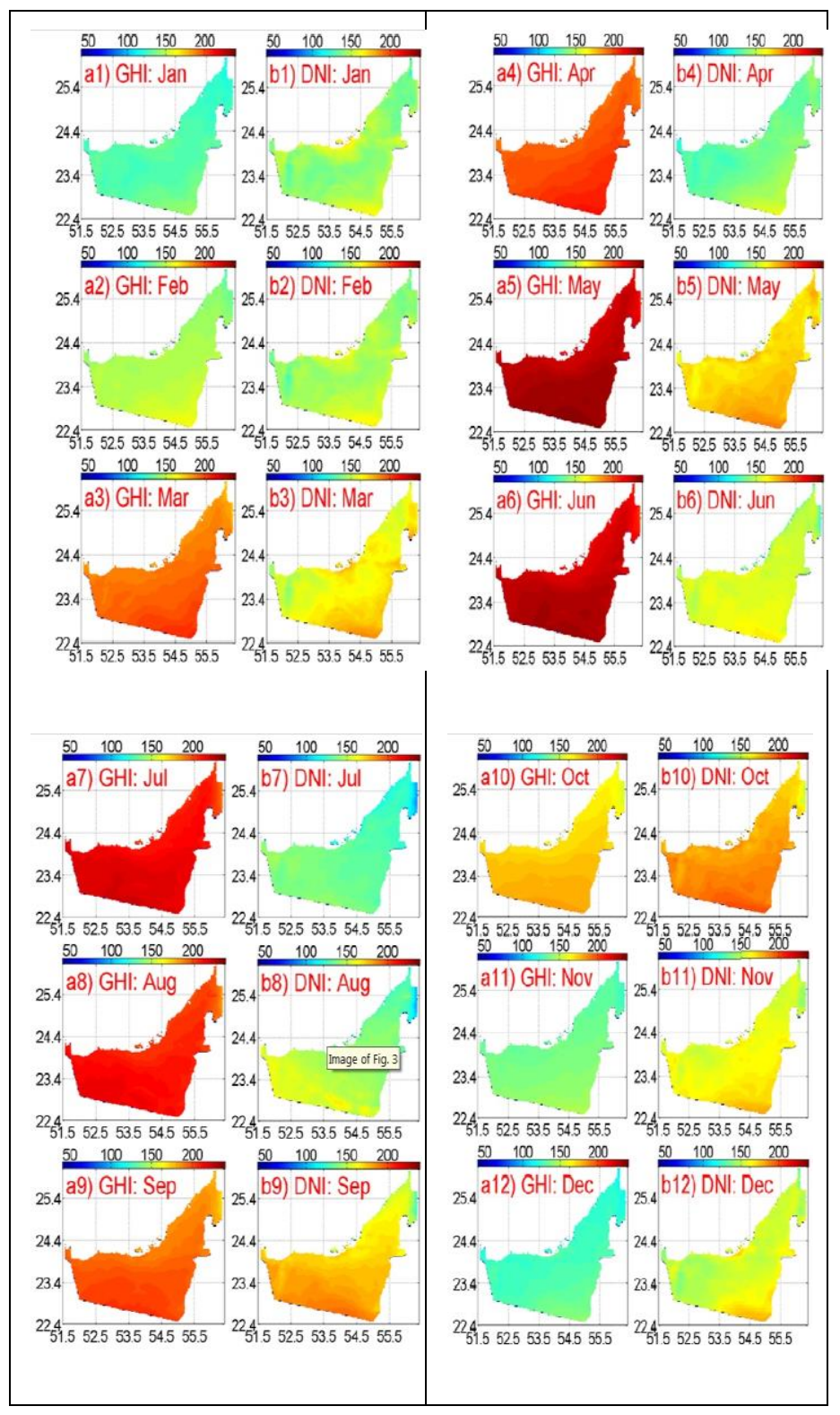

Fig. 6. Monthly Avg. of GHI, DNI in $\mathrm{KWH} / \mathrm{m}^{2}$.

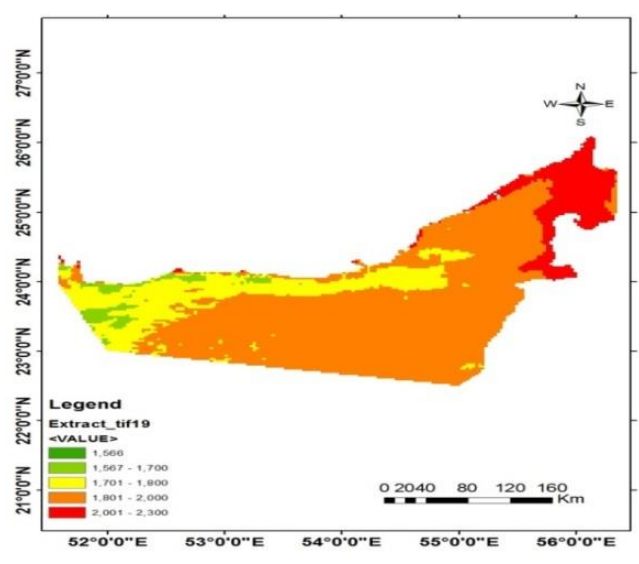

Fig. 7. UAE annual sum of DNI

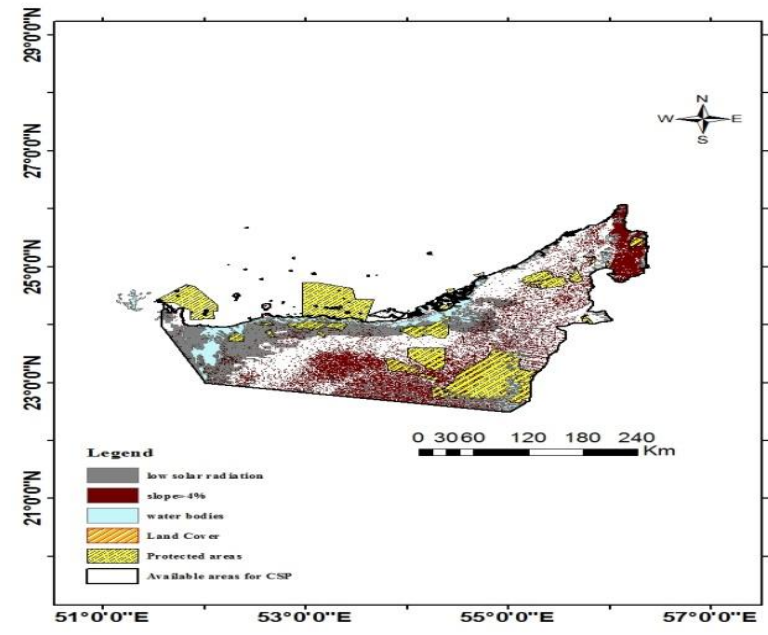

Fig. 8. UAE exclusion map.

The above exclusion maps shown in Fig. 8 are accumulated in one map that includes all inclusion criteria's. The areas that don't represent any of the above exclusion criteria will be considered as available areas to install CSP projects. Fig. 8 shows the exclusion areas, where the white colored pixels represent suitable places to install CSP projects which will be the main target for ranking criteria in the next section.

\section{2) Ranking Suitable Area}

In this section, the research will define ranking criteria to be used within MCDM. The MCDM will identify the hotspots within suitable areas shown in Fig. 8. The ranking criteria determine the weights for each criterion, and then determine main hot-spots within that area. The main idea of ranking criteria is to give a weight to each ranking factor; this weight is calculated depending on how much the factor is important as compared to other factors. The factor may have conflicted objective with other factors, therefore, it is recommended to install solar projects at high solar irradiation areas, but these areas may have a high elevation that makes the installation process difficult and costly. Through-out the research it will be considered the following factors: irradiation level, water availability, proximity to roads and power grid as well as slope.

\section{A. Solar Irradiation}

As mentioned in the previous section the solar radiation is the main source for solar power technology. The sites that have higher levels of DNI will have great impact in the feasibility of solar projects. The map is classified with interval of $50 \mathrm{KWh} / \mathrm{m}^{2}$ as annual radiation. We have got 10 radiation interval, each interval had been assigned a value from $0-10$ according to its importance as shown in Table I.

TABLE I. ANNUAL DNI RANKING CRITERIA

\begin{tabular}{|l|l|l|l|l|l|l|l|l|l|l|}
\hline & & 18 & 18 & 19 & 19 & 20 & 20 & 21 & 21 & \\
Irradi & $<18$ & $00-$ & $50-$ & $00-$ & $50-$ & $00-$ & $50-$ & $00-$ & $50-$ & $>22$ \\
ation & 00 & 18 & 19 & 19 & 20 & 20 & 21 & 21 & 22 & 00 \\
& & 50 & 00 & 50 & 00 & 50 & 00 & 50 & 00 & \\
\hline Score & 0 & 2 & 3 & 4 & 5 & 6 & 7 & 8 & 9 & 10 \\
\hline
\end{tabular}




\section{B. Water Availability and Proximity to Water Sources}

In CSP technology, the water is necessary for cooling operation of CSP plants. The CSP uses the thermal energy absorbed from the solar field that is used to drive the turbines. Therefore, it is recommended for CSP projects to be built near water sources in order to make the project techno-economic feasible. In Table II, the water sources proximity were assigned scores according to the closeness to the water bodies ranging from $0-10$. Remembering that the water body itself is excluded from the ranking process, it has been considered as an exclusion area. Furthermore, a buffer zone of $20 \mathrm{Km}$ was applied to the processed map, where the pixels inside buffer zone has score from 2-10, and the pixels outside buffer zone are assigned a score of 0 value.

TABLE II. PROXIMITY TO WATER BODIES RANKING CRITERIA

\begin{tabular}{|c|c|c|c|c|c|c|c|c|c|c|}
\hline $\begin{array}{l}\text { Distance } \\
(\mathbf{K m})\end{array}$ & $\begin{array}{l}0- \\
2\end{array}$ & $\begin{array}{l}2 \\
- \\
4\end{array}$ & 6 & 8 & $\begin{array}{l}8- \\
10\end{array}$ & $\begin{array}{l}10 \\
- \\
12\end{array}$ & $\begin{array}{l}12 \\
- \\
14\end{array}$ & $\begin{array}{l}14 \\
- \\
16\end{array}$ & $\begin{array}{l}16 \\
- \\
20\end{array}$ & $>20 \mathrm{Km}$ \\
\hline Score & 10 & 9 & 8 & 7 & 6 & 5 & 4 & 3 & 2 & 0 \\
\hline
\end{tabular}

\section{Distance from Roads}

The roads play significant role in any project or service intended to be supplied. The proximity to the roads presented in Table III determines the installation cost of the solar projects; therefore, when starting to build a site, the vehicles need roads for their easy access to the site. Furthermore, when the site is close to the roads, then the maintenance cost will be less as compared to the remote sites. Remote sites need additional cost represented by constructing new roads to access the sites. Fig. 9 shows the main roads within UAE, this map will be used to construct the overall suitability map [9].

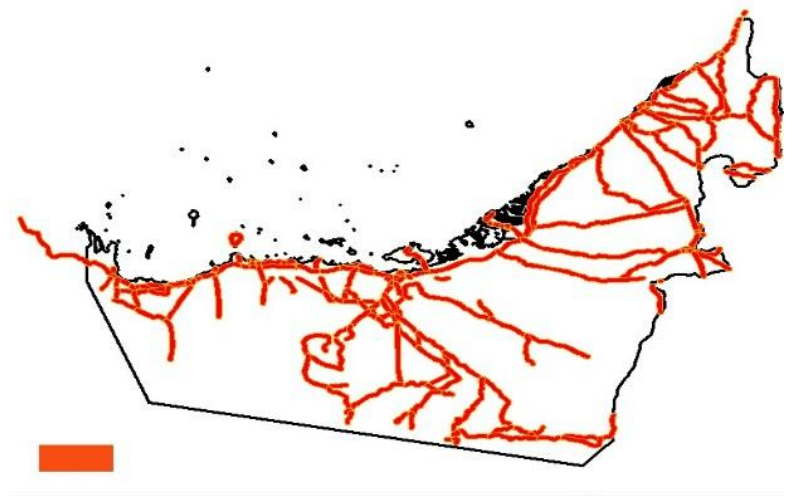

Fig. 9. UAE roads map.

TABLE III. PROXIMITY TO ROADS RANKING CRITERIA

\begin{tabular}{|l|r|r|c|c|c|}
\hline Distance (Km) & $0-5$ & $5-10$ & $10-15$ & $15-20$ & $>20 \mathrm{Km}$ \\
\hline Score & 10 & 9 & 8 & 7 & 1 \\
\hline
\end{tabular}

In this paper, a buffer zone of $20 \mathrm{Km}$ was considered for a main target of this study. So the distances greater than $20 \mathrm{Km}$ were given a low score equal to 1 , while the distances less than $20 \mathrm{Km}$ were given a high score $(2-10)$ reciprocal to the closeness.

\section{Distance from Transmission Lines}

The proximity to the power grid is an important feasibility factor in the project planning phase. Solar projects need to be connected to the high voltage power grid. There, where the power grid is not exist, the project managers need to install transformers as well as running high quality cables for the national power grid which represent additional cost to the project. Fig. 10 illustrates the main power transmission lines within UAE, whereas this map will be used to construct the overall suitability map.

Throughout the research a surrounding area with $40 \mathrm{Km}$ was considered as a buffer zone around the transmission lines. A high scores from (3-10) were given in Table IV to pixels inside buffer zone while a low score (equal 0 ) were given to the pixels out of the buffer zone. Accordingly, the manager at the project plan phase should look for sites that are close to the power grid in order to reduce cost and increase the project feasibility.

TABLE IV. PROXIMITY TO TRANSMISSION LINE RANKING CRITERIA

\begin{tabular}{|l|l|l|l|l|l|l|l|l|}
\hline & 0 & 5 & 0 & 5 & 0 & 5 & 0 & 5 \\
Distance (Km) & - & - & - & - & - & - & - & - \\
\hline Score & 5 & 10 & 15 & 20 & 25 & 30 & 35 & 40 \\
\hline
\end{tabular}

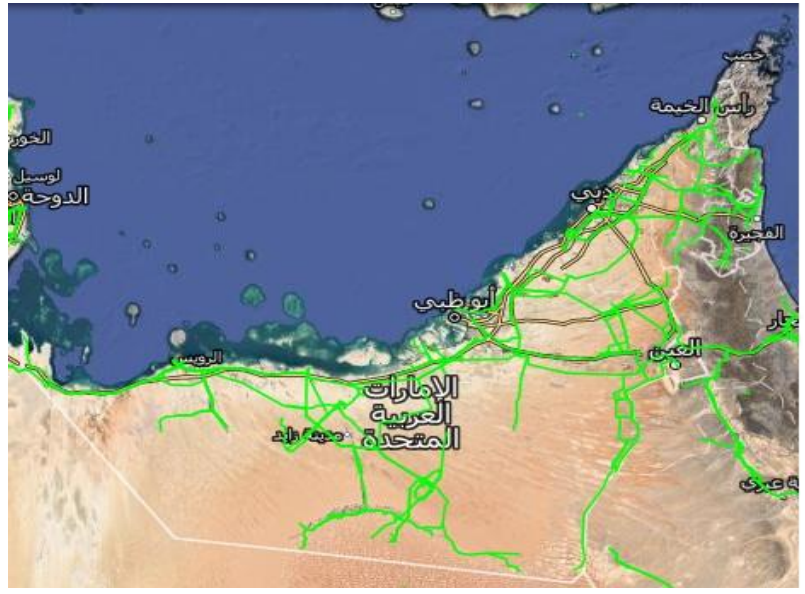

Fig. 10. UAE power lines map.

All the above mentioned factors can be represented as GIS map layer, where the GIS technique enables the combination of above conditions. Hence, the decision criteria are defined based on relative weight as a result of using AHP method. Map's layers are digitized then overlaid on the top of each other, thus the final map will show the occupied areas as well as free areas (suitable regions).

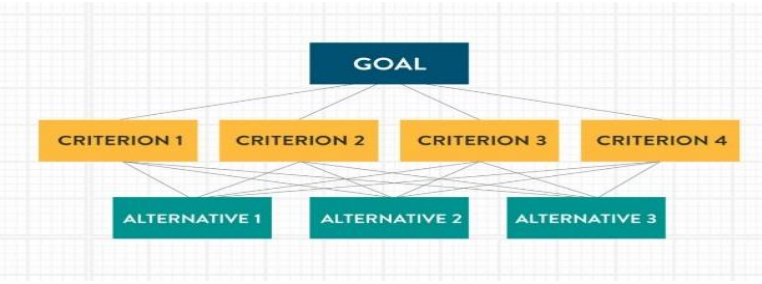

Fig. 11. AHP hierarchy. 
AHP is multi-criteria decision making divided the problem into small parts then construct hierarchy in which the goal is in the top and criteria in the sub-level of hierarchy, where each level has adequate weight and the alternatives exist in the bottom of hierarchy, Fig. 11. The best alternative is chosen by performing series of activities in order to select best alternative from multi-alternatives [10].

TABLE V. RATIO SCALE FOR PAIR WiSE COMPARISON OF IMPORTANCE

\begin{tabular}{|l|l|}
\hline Significance & Definitions \\
\hline 1 & Same importance \\
\hline 3 & Moderate importance \\
\hline 5 & Strong importance \\
\hline 7 & Very strong importance \\
\hline 9 & Extreme importance \\
\hline $2,4,6,8$ & $\begin{array}{l}\text { Intermediate value between the above adjacent } \\
\text { values }\end{array}$ \\
\hline
\end{tabular}

The first step in AHP techniques is to construct the decision hierarchy in which the decision consists of the objective for criteria then sub-criteria and finally the goal. The goal is represented at the top, whereas the criteria and subcriteria are represented at the middle and the alternatives are at the lowest level.

The next step is to set the priorities at each level, multicomparison matrices of all levels with respect to higher level that are made [11]. The pairwise comparisons are set according to how much " $\mathrm{X}$ " element is more important than "Y ", the preferences are given numbers using nine-point scale based on Saaty's pairwise comparison shown in Table V.

The next step is to generate the matrix of ranking for each level (based on Saaty's pairwise comparison as shown in Table V. After that the relative weights called Eigen vectors are obtained.

The matrix is constructed as comparison between objectives denoted by $\left(A_{1}, A_{2}, \ldots, A_{n}\right)$ and their weights denoted by $\left(\mathrm{W}_{1}, \mathrm{~W}_{2}, \ldots, \mathrm{W}_{\mathrm{n}}\right)$. Table VI represents the pairwise comparisons matrix [12].

TABLE VI. MATRIX CONTAINING WeIGHTS

\begin{tabular}{|l|l|l|l|l|}
\hline & $\mathrm{A}_{1}$ & $\mathrm{~A}_{2}$ & $\ldots \ldots$ & $\mathrm{A}_{\mathrm{n}}$ \\
\hline $\mathrm{A}_{1}$ & $\mathrm{~W}_{1} / \mathrm{W}_{1}$ & $\mathrm{~W}_{1} / \mathrm{W}_{2}$ & & $\mathrm{~W}_{1} / \mathrm{W}_{\mathrm{n}}$ \\
\hline $\mathrm{A}_{2}$ & $\mathrm{~W}_{2} / \mathrm{W}_{1}$ & $\mathrm{~W}_{2} / \mathrm{W}_{2}$ & & $\mathrm{~W}_{2} / \mathrm{W}_{\mathrm{n}}$ \\
\hline$\cdot$ & & & & \\
$\cdot$ & & & & \\
\hline$\cdot$ & & & & $\mathrm{W}_{\mathrm{n}} / \mathrm{W}_{\mathrm{n}}$ \\
\hline $\mathrm{A}_{\mathrm{n}}$ & $\mathrm{W}_{\mathrm{n}} / \mathrm{W}_{2}$ & $\mathrm{~W}_{\mathrm{n}} / \mathrm{W}_{2}$ & & \\
\hline
\end{tabular}

The above matrix has a positive entries, if we multiply the above matrix by matrix $\mathrm{W}^{\mathrm{T}}$ ( $\mathrm{W}$ transpose), the result is the victor $\mathrm{nW}$, where $\mathrm{AW}=\mathrm{nW}$.

Table VI presents the A matrix that is a unity rank, where each row is considered to a constant value multiplied by first row. $A w=\lambda w$, the difference, if any, between $\lambda_{\max }$ and $\mathrm{n}$ is an indication of the inconsistency of the judgments. If $\lambda_{\max }=n$ then the judgments have turned out to be consistent.

The solution of $\mathrm{W}$ is any column of $\mathrm{A}$, this solution is normalized so the total sum is equal to zero as shown in (1).

$$
(\mathrm{A}-\lambda \max ) \mathrm{W}=0 \text {, if } \sum \mathrm{Wi}=1
$$

The largest Eigen-Value of the above Matrix denoted by $\left(\lambda_{\max }\right)$ is calculated as shown in (2).

$$
\lambda \max =\frac{1}{n} \sum_{i=1}^{n} \frac{(A W) i}{W i}
$$

Furthermore, matrix A satisfied consistency property represented by (3).

$$
\text { Consistency ratio } \mathrm{CR}=\mathrm{CI} / \mathrm{RI}
$$

Where CI is consistency index $\left(\mathrm{CI}=\left(\lambda_{\max }-n\right) /(n-1)\right)$, and $\mathrm{RI}$ is a random consistency index having fixed values as listed in Table VII. The value of $\mathrm{CR} \leq 0.10$ indicates that consistent exists.

TABLE VII. VALUES OF RI INDEX

\begin{tabular}{|l|l|l|l|l|l|l|l|l|}
\hline $\mathrm{n}$ & & 2 & 3 & 4 & 5 & 6 & 7 & 8 \\
\hline $\mathrm{RI}$ & & 0 & 0.52 & 0.89 & 1.11 & 1.25 & 1.35 & 1.4 \\
\hline
\end{tabular}

\section{EVALUATION AND RESULTS OF APPLYING MCDM TO RANK SUITABLE AREAS}

The GIS layers are now improved for selecting the suitable site for installing solar projects. In order to apply GISprocessing to the GIS layers, a weights are required to scale each layer to get suitability (Hot-Spots) Map. MCDM technique could be applied to the factors in order to get the required weights MCDM follow pre and post steps in order to get the required weights as follows:

\section{Step 1: Set the goal / defined the problem}

The goal should be specific, measurable, and relevant and time bounded. The main goal here is to attain overlay measurable weights which are relevant to be applied to the GIS-layers in order to get the hot-spots map specific.

\section{Step 2: Determination of the criteria and constrains.}

Throughout the previous sections the study discussed the factors as well as constrains, where the factors were the solar irradiation (DNI), terrain elevation represented by slope, as well as proximity to the roads, water bodies and power grids. The constraints were the protected areas, water bodies, land cover areas and low solar radiation areas as well as steep areas [13].

\section{Step3: Standardize the factors-criterion scores}

Throughout the research the study has combined multifactors in different measurement scale, for instance the slope is percentage value while elevation is measured by meters and so on. To tackle this problem each factor was reclassified to standard range in which each interval is represented by standard value according to its importance.

\section{Step 4: Determine the weight of each factor}

AHP is represented by importance matrix that contains a comparison between criterion (factors) shown in Table V. The decision matrix values had been determined according to literature studies in this field based on international experts' opinions. The weights are calculated based on the related formula, then the result used to calculate a consistency ratio 
(CR) of the pairwise comparisons by equation $\mathrm{CR}=\mathrm{CI} / \mathrm{RI}$ mentioned above. The CR must be less than $10 \%$ to ensure consistency. Otherwise the process is not consistent and the summation of overall weights is equal to 1 . Tables VIII and IX show the calculations of AHP decision required to determine factors weights in addition to main criteria and sub-criteria. The consistency of the factors is less than $10 \%$, which means that the estimation is consistent such that [14]:

- $\mathrm{CR}=\mathrm{CI} / \mathrm{RI}, \mathrm{CI}=\left(\lambda_{\max }-\mathrm{n}\right) /(\mathrm{n}-1)$, so $\mathrm{CI}=(3.065-3) /$ $(3-1)=0.0325$.

- $\mathrm{CR}=0.0325 / 0.52=0.0625$

- Weights $w$ can be found by solving the matrix $(A-\lambda)$ $\mathrm{w}=0$ (Table VIII).

- $\mathrm{CR}=((3.018-3) /(3-1)) / 0.52=1.7 \%$.

- Weights w can be found by solving the matrix $(\mathrm{A}-\lambda)$ $\mathrm{w}=0$, Table IX.

\section{Step 5: Aggregate the criteria}

The aggregation is made by linear combination of all weights multiplied by constraints Boolean value. Equation (4) represents the decision role:

$$
\mathrm{S}=\sum \text { wi. } \mathrm{xi} \times \prod \mathrm{cj}
$$

Where, S - aggregate suitability score, xi - pixel's factor value (radiation, slope, proximity), wi - weights of factor, $\mathrm{cj}-$ constraints (exclusion areas), product of constraints (1-suitable area, 0-unsuitable area).

TABLE VIII. AHP METOD To DeCISION MAIN CRITIRION (FACTORS): THE PAIRWISE COMPARISON MATRIX.

\begin{tabular}{|c|c|c|c|c|c|}
\hline $\begin{array}{l}\text { Factor } \\
\text { (criteria) }\end{array}$ & $\begin{array}{l}\text { Decision } \\
\text { matrix }\end{array}$ & $\begin{array}{l}\text { Eigen } \\
\text { value }\end{array}$ & $\begin{array}{l}\text { Eigen } \\
\text { vector } \\
\text { solution }\end{array}$ & $\begin{array}{l}\text { Consistency } \\
\text { Ratio CR }\end{array}$ & Weights \\
\hline $\begin{array}{l}\text { Solar } \\
\text { irradiation }\end{array}$ & $\begin{array}{cc}1 & 3 \\
0.33 & 1\end{array}$ & 3.065 & $\begin{array}{l}4 \\
\text { iterations }\end{array}$ & $6.25 \%$ & $64.9 \%$ \\
\hline Slope & $0.14 \quad 0.2$ & 1 & , delta $=$ & & $27.9 \%$ \\
\hline Proximity & & & $2.6 \mathrm{E}-8$ & & $7.2 \%$ \\
\hline
\end{tabular}

The results we have got from Step 4 were applied into (5) of Step 5 using ArcGis maps software (Raster calculator command). The final result is the maps shown below in Fig. 12, the red areas represent hot-spots areas within Dubai Emirate, while the orange represent the suitable areas, the green color represent moderate and less suitable areas (notsuitable).

\section{Step 6: Verify the results}

Site survey is a method to validate the results, fortunately UAE have implemented two large-scale successful projects and on coming project in swihan, where the implemented projects exist in: Masdar City and Shams1 solar projects [14][16].

It is evident from Fig. 12 that the two projects in orange areas and macaw green areas are suitable and moderate suitable areas for successful implementing large-scale CSP projects in UAE. It is good to mention here that one of the most successful CSP projects known as "Swihat project" has been already installed in this orange area. This improve that the results we gained are valid [17].

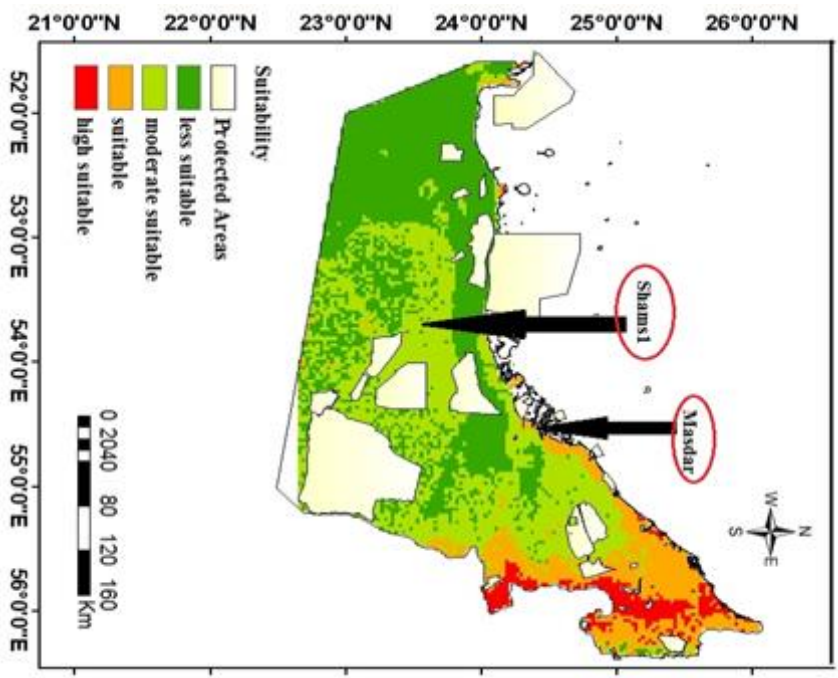

Fig. 12. UAE solar suitability map.

\section{CONCLUSION}

Identifying the optimal location to install CSP solar project in UAE is the main concern of this paper, in terms of low cost, right location, low risk as well as appropriate delivering time.

A combination between GIS-maps and MCDM-AHP approach has been adapted in order to determine the optimal location to house large-scale solar CSP projects in UAE. This is the first study to identify suitability map for large-scale CSP solar locations using GIS-MCDM technique on a country level of UAE.

The research answered the main question of this study "where and how to determine the suitable locations to install large scale solar projects in UAE?" The decision factors, including exclusion areas plus ranking suitable areas, are the key elements to generate the suitability map.

To mask unsuitable areas, the study has identified five exclusion criteria (i.e. protected areas, land cover areas, topography, water bodies, and low solar radiation). Only three main ranking criteria have been included (i.e. sola irradiation, slope of the area and accessibility). Concerning the accessibility, three sub-criteria have been identified (i.e. proximity to roads, proximity power transmission lines and proximity to water sources) [18].

The AHP approach has been applied to determine the relative weights of the decision-criteria and the final weights of the ranking criteria. Then the combination between GIS data and AHP approach was used to determine the potential areas to install large-scale solar projects. The suitability maps show that Dubai Emirates has more suitability for CSP projects, whereas the hotspot areas to install CSP projects are shown in red color on the map [19].

The study prepared in this research can help policy and decision makers to adapt suitable policies as well as suitable locations for renewable investments. 
TABLE IX. AHP METHOD TO DECISION SUB-CRITIRON (FACTORS)-PROXIMITY

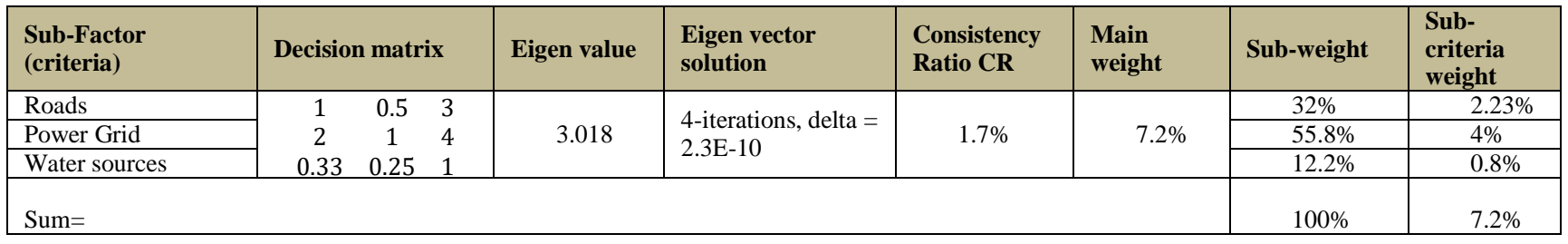

\section{REFERENCES}

[1] D. R. JALILVAND, "Renewable Energy forthe Middle East and North Africa", Friedrich-Ebert-Stiftung, Amman, 2012.

[2] S. S. A. B. Ahmed Aly, "Solar Power Potential in Tanzania”, elsevier, Amestrdam, Holand, 2017.

[3] Marei, I., "The law and policy for electricity generated by rnewable energy: Grenning the power in three middle eastern Jurisdictions", Ms.C. thesis. Brisbane, Australia: Queensland University of Technology, 2015.

[4] IUCN, "Protected areas", International union for conservation of nature IUCN, 2008.

[5] WDPA, "protected planet", 14 october 2017. https://www.protectedplanet.net/country/AE.

[6] European space Agency ESA, "ESA", 2009. http://due.esrin.esa.int/page_globcover.php.

[7] L. a. Doll, "Global lakes and wetlands database", 17 Oct. 2017. https://www.worldwildlife.org/publications/global-lakes-and-wetlandsdatabase-lakes-and-wetlands-grid-level-3.

[8] Gherboudj I, Ghedira H, "assessment of solar energy potential over UAE”, ELSEVIER, 2015

[9] IRENA, "RECREMA", 2017. https://atlas.masdar.ac.ae/.

[10] o. s. m. f. OSMF, “open street map”, 2017. https://goo.gl/1EtZRh.

[11] M. Stojanovic, "multi-criteria decision-making for selection of renewable energy system”, saftey engineering, pp. 115-120, 2013

[12] M. STOJANOVIĆ1, "MULTI-CRITERIA DECISION-MAKING FOR SELECTION OF RENEWABLE ENERGY SYSTEM", www.safety.ni.ac.rs, 2013.

[13] P. Kousalya, Analytical Hierarchy Process approach - An application of engineering education

[14] DECC, "Statistical Data Set - Industrial energy price statistics", 2014.

[15] N. W. Station, "Solar PV Geneartion - Live Performance Data", 2014.

[16] A. Haque, M. Rahman, and Q. Ahsan, "Building Integrated Photovoltaic system: Cost effectiveness", in Electrical \& Computer Engineering (ICECE), 2012 7th International Conference on, 2012, pp. 904-907.

[17] M. Koller, T. Borsche, A. Ulbig, and G. Andersson, "Defining a degradation cost function for optimal control of a battery energy storage system", in PowerTech (POWERTECH), 2013 IEEE Grenoble, 2013, pp. 1-6.

[18] F. O'Flaherty, J. Pinder, and C. Jackson, "Determination of payback periods for photovoltaic systems in domestic properties", 2012.

[19] Z. Wu, X.-P. Zhang, J. Brandt, and S. Zhou, "Three Control Approaches for Optimized Energy Flow with Home Energy Management System", IEEE Power and Energy Technology Systems Journal 2015. 